Rhode Island College

Digital Commons @ RIC

\title{
A Policy Analysis of the Nursing Shortage in Selected Sub- Saharan African Countries
}

Julia Twining

Rhode Island College

Follow this and additional works at: https://digitalcommons.ric.edu/etd

Part of the Other Nursing Commons

\section{Recommended Citation}

Twining, Julia, "A Policy Analysis of the Nursing Shortage in Selected Sub-Saharan African Countries" (2010). Master's Theses, Dissertations, Graduate Research and Major Papers Overview. 70.

https://digitalcommons.ric.edu/etd/70

This Major Paper is brought to you for free and open access by the Master's Theses, Dissertations, Graduate Research and Major Papers at Digital Commons @ RIC. It has been accepted for inclusion in Master's Theses, Dissertations, Graduate Research and Major Papers Overview by an authorized administrator of Digital Commons @ RIC. For more information, please contact digitalcommons@ric.edu. 
A POLICY ANALYSIS OF THE NURSING SHORTAGE IN SELECTED

\section{SUB-SAHARAN AFRICAN COUNTRIES}

A Major Paper Presented

By

Julia Twining, RN, BSN, OCN

Approved:

Committee Chairperson

Committee Members
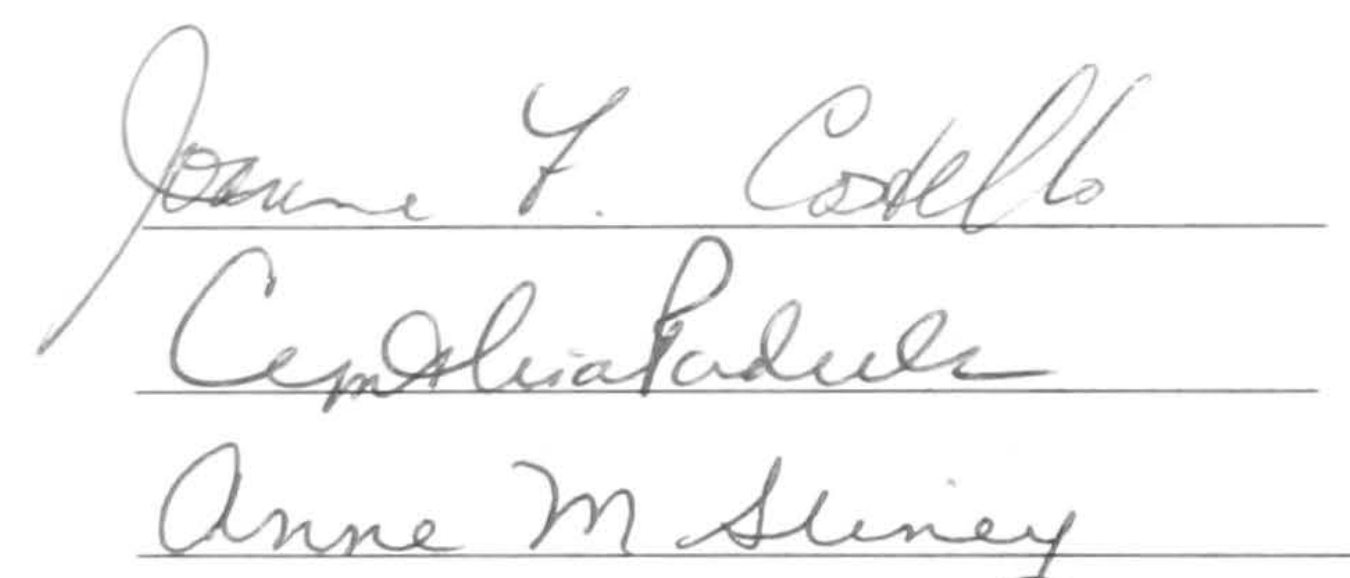

Director of Master's Program

Dean, School of Nursing

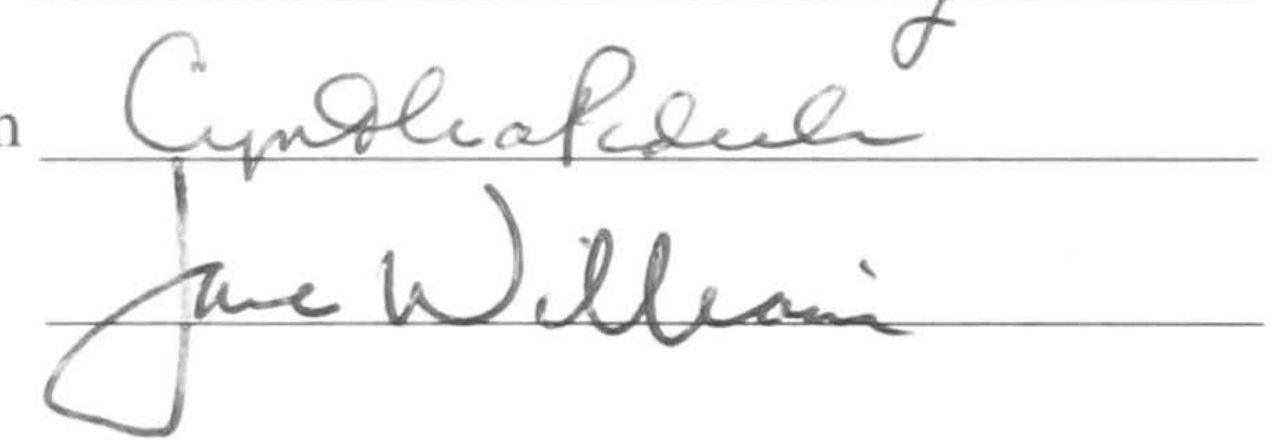

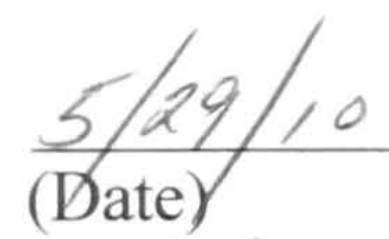

clidio

(Date)

$\frac{5 / 29 / 10}{\text { (Date) }}$

$\frac{6 / 10 / 10}{\text { (Date) }}$

$\frac{7 / 29 / 10}{\text { (Date) }}$ 
A POLICY ANAL YSIS OF THE NURSING SHORTAGE

IN SELECTED SUB-SAHARAN AFRICAN COUNTRIES

$$
\text { by }
$$

Julia Twining, RN, BSN, OCN

A Major Paper Submitted in Partial Fulfillment

of the Requirements for the Degree of

Master of Science in Nursing

in

The School of Nursing

Rhode Island College

2010 


\begin{abstract}
This paper will begin with a comprehensive literature review of the nursing shortage in the sub-Saharan African region. The global nursing crisis is explored with a focus on the economics of nursing, challenges presented by the nursing shortage, interventions to increase nursing capacity, and partnerships that have been implemented to achieve this goal. The nursing shortage in selected sub-Saharan African countries is analyzed from a policy perspective using Fawcett and Russell's Conceptual Model of Nursing and Health Policy (2005). Then, McLaughlin and McLaughlin's Policy Analysis Process (2008) is used to identify, analyze, evaluate, and make recommendations to create health policy. The primary thrust is to advocate for sustainable interventions that will assist in alleviating the nursing shortage in selected sub-Saharan African countries.
\end{abstract}


Acknowledgements

To Cindy Padula, PhD, thank you for your wisdom, guidance, and editorial skills. I am a better writer because of what I learned from you.

To Joanne Costello, $\mathrm{PhD}$, thank you for your example, support, and friendship over the past three years. I have learned much from you in and out of class.

To Anne Sliney, RN, BSN, PhD (h.c.), Chief Nursing Officer for the Clinton Foundation, thank you for the opportunity to learn from you and learn about the possibilities in global health. You are an inspiration for what a nurse can do to benefit the health and lives of those in need.

To my husband Jonathan and my son Jonathan Jared, thank you for your love and support over the past three years. With everything I do, I hold you in my heart. I love you more than words can say. 
Table of Contents.

Page

Background and Problem Statement..................................................

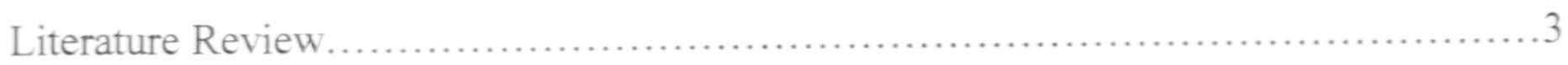

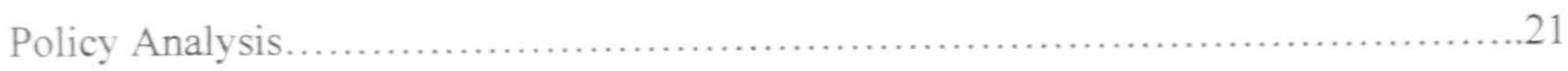

Summary, Conclusions and Implications for Advanced Practice Nursing................39

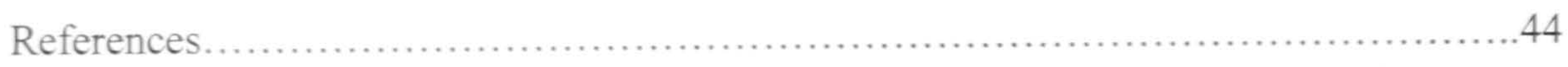


A Policy Analysis of the Nursing Shortage in Selected sub-Saharan African Countries Background and Problem Statement

Policy advocacy is a critical nursing role that has deep roots in the nursing profession beginning with Florence Nightingale, Lillian Wald, and Margaret Sanger. Policy advocacy as defined by Spenceley, Reutter, and Allen (2006) is action that is knowledgebased with the goal of improving health by changing decisions made at the system level. The ethical mandate for nurses to use their unique knowledge base to impact health and health care globally has been seen as an immediate need (Spenceley et al., p. 185).

The nursing workforce in the sub-Saharan African region is impacted by health policy established by each country. The nursing shortage requires analysis of current policies and development of more effective, efficient, and equitable policies to provide sustainable solutions to increase the nursing capacity of these countries. Fawcett and Russell (2001) defined policy by choices and priorities using the following definition: "the choices that a society, segment of society, or organization makes regarding its goals and priorities and how it will allocate its resources" (p. 112). Health policy can be more specifically defined as a type of public or social policy that has a direct or indirect impact on people's health with intended or unintended consequences (Fawcett \& Russell).

Fawcett and Russell (2001) stated that health policy is comprised of three components: 1) health services; 2) health care personnel; and 3) health care expenditures. The component of health care services addresses the quality of and access to health care. Quality health care and access to quality health care can have a significant positive impact on health indicators. Conversely, lack of quality health care and lack of access to 
quality health care can have a negative impact on health indicators. In relation to the identified topic, policy specific to health care personnel would examine the inefficiency in nursing educational preparation and the 'push/pull' influences impacting nurses to leave their country of origin to seek a higher level of employment opportunity in more developed countries. Health care expenditures, including providing funds for salaries for nurses, are a source of significant direct and indirect costs to the governments of the subSaharan African region. In addition, most of these governments do not make investment in nursing a priority when allocating funds to support health care.

The nursing shortage calls for sustainable policies to increase nursing capacity such as: increasing the number of nurse educators; expanding the infrastructure of nursing schools to accommodate a larger number of nursing students; streamlining the education requirements to work as a registered nurse; and establishment of sustainable iniatives to motivate the nursing workforce to remain in the country of origin. Nurses represent the largest segment of the health profession and nurses are usually the 'front line staff' treating the community. The contribution of nurses is required to help meet the Millennium Development Goals (MDGs) and to deliver health care that is safe and effective (Buchan \& Calman, 2004). 
Literature Review

\section{Health Indicators in sub-Saharan Africa}

The sub-Saharan African region, on the continent of Africa, lies below the Sahara desert and is made up of 48 countries, including the islands of Cape Verde, Sierra Leone, Ghana and the Republic of Congo in the west, South Africa, Lesotho, and Swaziland to the South, Mozambique, Tanzania, Kenya and the island of Madagascar in the east, and Sudan, Chad, Niger and Mali in the Northern region (World Bank, 2009). While each country has unique health care needs, there are common communicable and noncommunicable diseases found in the sub-Saharan African region.

Communicable diseases. Three of the most significant communicable diseases are HIV/AIDs, malaria, and tuberculosis. Malaria and tuberculosis are often concurrent illnesses with HIV/AIDs in this region (Global Health Workforce Alliance [GHWA], 2009). Table 1 illustrates the HIV/AIDs death rate and the incidence for tuberculosis for five sub-Saharan countries and the United States.

Table 1

HIV/AIDs death rate and Tuberculosis (TB) incidence for five sub-Saharan countries and the United States

\begin{tabular}{|l|l|l|}
\hline Country & $\begin{array}{l}\text { HIV/AIDs death rate per } \\
100,000 \text { population } 2005\end{array}$ & $\begin{array}{l}\text { Incidence for TB per } \\
100,000 \text { population 2006 }\end{array}$ \\
\hline Kenya & 409 & 384 \\
\hline Malawi & 605 & 377 \\
\hline South Africa & 675 & 940 \\
\hline Zambia & 840 & 557 \\
\hline Botswana & 1020 & 551 \\
\hline US & 5 & 0 \\
\hline
\end{tabular}

Source: WHO (2008) 
Botswana has the highest HIV/AIDs death rate, 1020 per 100,000 population, and Kenya has the lowest death rate, 409 per 100,000 population. When looking at the incidence for TB, South Africa has the highest incidence rate, 940 per 100,000 population and Kenya has the lowest incidence rate, 384 per 100,00 population. In sub-Saharan Africa, the HIV/AIDs pandemic has placed these countries into a severe health crisis, where the goal of a significant portion of the population is focused on survival. In countries with a high incidence rate, life expectancy has significantly declined and infant and child mortality has increased (Chen \& Evans, 2004). Ten years after HIV prevalence increases, deaths from AIDs will increase, which has a profound effect on society. These include that families disintegrate, children become orphans, education and health are interrupted, economic growth is slowed, and governments face challenges (Chen \& Evans). In the Southern African region, hunger and food insecurity have increased because of AIDs. Within the HIV positive population, tuberculosis is increasing due to compromised immune systems and multidrug resistant strains becoming more prevalent. Today, malaria is becoming more widespread and resistant to available treatment. Also, common childhood infectious diseases increase when basic immunizations are not maintained (Chen \& Evans).

Non-communicable diseases. The three most serious non-communicable diseases presenting public health challenges include diabetes, cardiovascular disease, and cancer, which are often seen as chronic diseases. Deaths from these chronic diseases account for $80 \%$ of the deaths in low and middle-income countries around the world (African Health 
Monitor, 2008). In 2005, the estimated number of chronic disease-related deaths in the WHO African Region was 2,446,000 (African Health Monitor).

Over the next ten years, the WHO also estimates that 28 million people will die from chronic disease in the WHO African Region, and the deaths caused by diabetes will rise by $42 \%$ (African Health Monitor). In 2006, in Africa, the estimated number of people with diabetes was 10.4 million and by 2025 the number of people with diabetes is expected to rise to 18.7 million people. Unfortunately, most people with diabetes go undiagnosed; in Cameroon, Ghana, and Tanzania, the estimated cases of undiagnosed diabetes are estimated to be 60\%-80\% (African Health Monitor). With undiagnosed diabetes, serious complications develop, including renal failure, retinopathies, foot disease, and heart disease, which can lead to disability and death. The mortality rate is high in some countries in Africa at greater than 40 per 10,000 population (African Health Monitor).

Cardiovascular disease affects more than 20 million people in the African region and most people affected live in urban areas (African Health Monitor, 2008). In adults 25-65 years of age, the prevalence is $25 \%$ to $35 \%$. In Ghana, Mauritius, South Africa, and Zimbabwe there has been an increase in hypertension, obesity, tobacco use and diabetes that could be contributing to the increase in stroke mortality. Preventing and controlling hypertension could decrease a minimum of 250,000 deaths each year (African Health Monitor). Public health nurses could play a key role in education and behavior modification, if there were an adequate number of nurses working in the public health arena. 
Cancer is a serious health issue in this region. For example, in 2002 in sub-Saharan Africa, 582,000 people were diagnosed with cancer (African Health Monitor, 2008). The most common types of cancer diagnosed in 2007 in women were Kaposi's sarcoma and breast and cervical cancer; the most common types in men were Kaposi's sarcoma and liver and prostate cancer (African Health Monitor). Interestingly, many would consider three of these five cancers to be preventable. For example, cervical cancer is closely related to human papiloma infection, which is a vaccine preventable disease (African Health Monitor).

Worldwide, when individuals who have been diagnosed with cancer have access to appropriate interventions and treatment, approximately one third of cancers can be prevented, one third can be cured, and one third cannot be cured (African Health Monitor, 2008). Diagnosis and treatment in Africa is dramatically different compared to the rest of the world. At the time of diagnosis, $80 \%-90 \%$ of individuals have incurable cancer, while the remaining $10 \%-15 \%$ are considered to have curable cancer with access to treatment (African Health Monitor). In 2002, the estimated deaths due to cancer in sub-Saharan Africa were 412,000. If prevention, intervention, and treatment are not significantly increased, it is estimated that by 2020 there will be 626,400 cancer related deaths (African Health Monitor).

Communicable and non-communicable diseases present a formidable challenge to health care delivery systems, particularly in sub-Saharan Africa. Four specific challenges to be overcome are: 1) the double burden of co-morbidities in communicable disease such as TB with AIDs and in non-communicable disease such as diabetes and 
cardiovascular disease; 2) chronic conditions like HIV/AIDs and diabetes place a burden on health care systems; 3 ) research shows there is an increase of more than one chronic condition, and having multiple chronic conditions creates additional challenges; 4) chronic disease places additional burdens on the primary health care framework (Bischoff, Ekoe, Perone, Slama, \& Loutan, 2009). A change in health care delivery is needed to meet the challenges presented by chronic diseases.

One such health care delivery change is advancing the role of nurses in the provision of care for chronic disease. Bodenheimer, MacGregor \& Stothart (2005) state, 'the health care literature and the experience of many efforts to improve chronic care indicate that nurses, not doctors, are the key to implementing the chronic care model in patient centered care. By nature of their education and role, nurses are in a position to champion transformation of chronic care.' Nurse-led programs demonstrate outcomes that are similar or better than outcomes produced by physician based chronic disease management (Bischoff et al, 2009). Research reveals that nurses have a vital role in chronic disease management. One example is patients who had lower mortality and lower incidence of adverse clinical events when they went to a diabetes clinic with a nurse compared to patients who received the standard care for diabetes (Bischoff et al, 2009). A Cochrane review in 2001 showed planned nursing visits improved healthy behaviors and outcomes in patients with diabetes. The review stated, 'nurses can even replace physicians in delivering many aspects of diabetes care, if detailed management protocols are available, or if they receive training' (Bodenheimer et al, 2005). Nurses providing planned care visits that result in positive outcomes may be the result of better 
communication with patients (Bischoff et al, 2009). Effective collaborative skills and the ability to create beneficial interaction with patients have also been cited as nursing skills which contribute to positive patient outcomes (Bischoff et al, 2009).

It is important for nurses to be prepared to meet the challenges presented by worldwide chronic diseases. In sub-Saharan Africa, nurses have a pivotal role in primary care coverage, particularly at the district and peripheral levels where there is scarce primary care doctor involvement (Bischoff et al., 2009). Two examples of chronic disease management in Cameroon demonstrate the impact nurses have on chronic diseases. The first example is a cross-sectional survey to evaluate provider-patient interaction in a rural health district in Cameroon. Nurses represented over $75 \%$ of the health care providers. This study revealed that patients had a better understanding of their illness when nurses gave additional explanations about the disease and concepts of illness. Additionally, most patients who understood the information related to their diagnosis were in agreement with the nurses about their diagnosis (Bischoff et al., 2009). The second example is a continuing education program with the goal of improving health education communication. The randomized trial demonstrated that the communication behavior of the intervention groups improved compared to the control group in these areas: paraphrasing, checking and back channeling responses, encouraging patients to speak, verifying whether a patient understood what was explained, reassuring and showing empathy, showing less disapproval, providing health education messages, and providing understandable explanations (Bischoff). Patients in the intervention group 
asked more questions, talked more easily about their lifestyle, and discussed HIV/AIDs more openly (Bischoff).

Nurses are in the position to lead and support models of chronic care (ICN, 2010). The International Council of Nurses (ICN) has analyzed two models of chronic care and the role of nurses. The first model, the Chronic Care Model (CCM) developed by Dr. E. Wagner, demonstrates the role of nurses and their influence in six elements of chronic care: 1) patient-provider relationship; 2) delivery system design; 3) decision support; 4) information systems; 5) community resources; and 6) health care organization (ICN, 2010). The second model is the WHO Innovative Care for Chronic Conditions (ICCC) framework that comprises 3 sets of 'building blocks': 1) health care organizations; 2) the community; and 3) policy environment. Nurses are in a position to contribute to each of these building blocks and provide effective care and manage chronic diseases by utilizing available resources (ICN, 2010). Within this framework, nurses demonstrate leadership in: giving patient education and information; establishing relationships with patients, patient caregivers, and communities; maintaining continuity of care; using technology to move patient care forward; supporting adherence to long-term treatment; and promoting collaboration with other health care professionals (ICN, 2010). Bischoff, et al, ask the poignant question: 'where are these nurses?' How does the shortage of nurses become integrated into policy development for preparing the nurse workforce in sub-Saharan Africa? (Bischoff et al., 2009). 


\section{Nursing Shortage in sub-Saharan Africa}

The nursing workforce in sub-Saharan Africa is a critical component to prevention, intervention, and treatment of communicable and non-communicable diseases. The subSaharan countries have tried to increase nursing capacity with available resources, but many obstacles need to be removed before nursing capacity can be sustainably increased. The nursing shortage in sub-Saharan Africa has significantly impacted the health outcomes of each country. The ratio of health care workers to population has a direct impact on the survival of women during childbirth and early infancy (World Health Organization [WHO], 2006) as well as other health indicators (Table 2).

Four of the eight Millennium Development Goals (MDGs), developed by the United Nations in 2009 are indicators of better health outcomes that can be directly influenced by nurses. These four MDGs include: reducing infant and under-five mortality by twothirds; reducing maternal mortality by three-fourths; halting and reversing HIV/AIDS, tuberculosis, and malaria epidemics; and reducing by half the people experiencing hunger (Buchan \& Calman, 2004). The World Health Organization (WHO, 2006) stated that the global shortage for health care workers totals approximately 4.3 million workers (including doctors, nurses, midwives, and other health professionals). The largest need is in sub-Saharan Africa, where an increase of $140 \%$ of health care workers is needed to overcome this shortage (WHO). It is important to note that sub-Saharan Africa has $11 \%$ of the world's population, $25 \%$ of the global burden of disease, $3 \%$ of the world's health workers, and less than $1 \%$ of the global health expenditure (WHO) (Table 3). 
Table 2

Health Indicators for five selected sub-Saharan African countries (WHO, 2008).

\begin{tabular}{|c|c|c|c|c|c|c|}
\hline $\begin{array}{l}\text { Health } \\
\text { Indicator }\end{array}$ & Year & Botswana & Kenya & Malawi & South Africa & Zambia \\
\hline $\begin{array}{l}\text { Maternal Mortality } \\
\text { Ratio per } 100,000 \\
\text { Live births }\end{array}$ & 2006 & 380 & 560 & 1100 & 400 & 830 \\
\hline $\begin{array}{l}\text { Infant Mortality } \\
\text { Rate per } 1,000 \text { live } \\
\text { births }\end{array}$ & 2006 & & & & & \\
\hline Female & & 88 & 70 & 72 & 54 & 101 \\
\hline Male & & 91 & 88 & 80 & 58 & 103 \\
\hline $\begin{array}{l}\text { Under } 5 \text { Mortality } \\
\text { Rate per } 1,000 \text { live } \\
\text { births }\end{array}$ & 2006 & & & & & \\
\hline Female & & 119 & 111 & 114 & 66 & 173 \\
\hline Male & & 128 & 130 & 126 & 72 & 190 \\
\hline $\begin{array}{l}\text { Deaths due to } \\
\text { HIV/AIDS } \\
\text { Per 100,000 } \\
\text { population } \\
\text { Per year }\end{array}$ & 2005 & 1020 & 409 & 605 & 675 & 840 \\
\hline $\begin{array}{l}\text { Prevalence of } \mathrm{HIV} \\
\text { Among adults } \\
>=15 \text { years } \\
\text { Per } 100,000 \text { population }\end{array}$ & 2005 & 23624 & 6125 & 12528 & 16579 & 15819 \\
\hline $\begin{array}{l}\text { Prevalence of } \\
\text { Tuberculosis } \\
\text { Per } 100,000 \text { population }\end{array}$ & 2006 & 454 & 334 & 322 & 998 & 568 \\
\hline $\begin{array}{l}\text { Nursing and Midwifery } \\
\text { Personnel Density per } \\
10,000 \text { population }\end{array}$ & 2004 & 27 & $\begin{array}{l}12^{*} \\
(2002)\end{array}$ & 6 & 41 & 20 \\
\hline
\end{tabular}


Table 3

The Global Nursing Shortage The WHO (2006)

\begin{tabular}{lccc|} 
Region & Countries with Shortages & Estimated Shortage & \% Increase Needed \\
\hline Africa & 36 & 817,992 & 139 \\
Americas & 5 & 37,886 & 40 \\
South East Asia & 6 & $1,164,001$ & 50 \\
Europe & 0 & NA & NA \\
Eastern & 7 & 306,031 & 98 \\
Mediterranean & 3 & 32,560 & 119 \\
Western Pacific & 3 & $2,358,470$ & 70 \\
Total & 57 & &
\end{tabular}

Educational preparation. Multiple barriers exist to becoming a nurse and continuing to practice as a nurse in many of the sub-Saharan countries. The many years required to become a registered nurse is one barrier found in many sub-Saharan countries. For example, in Kenya, a student can spend 9-12 years in nursing school to obtain a nursing degree and to be qualified to work as a registered nurse (Naruse et al., 2008). In Zambia, a high school graduate enters three years of training leading to a registered nurse diploma/certificate. Up to three additional years of practice and training are required to receive a registered midwifery certificate/diploma, and finally a minimum of one year of practice and three additional years of training are needed to obtain a bachelor of science (BS) in nursing degree. This is cumulatively 10 years of training and education to become a registered professional nurse (Munjana et al., 2005). 
Nursing workforce demands. Buchan and Calman (2004), in their report to the International Council of Nurses (ICN), identified three important areas to be addressed in regards to the nursing shortage: 1) the impact of HIV/AIDS; 2) internal and international migration of nurses; and 3) achieving health sector reform and reorganization. The impact of HIV/AIDS, with a marked increase in incidence, has been seen increasing sharply in patient populations. It has increased the workload for the existing nursing workforce and has also decreased the nursing workforce. A large percentage of nurses in some sub-Saharan countries have HIV/AIDS or are caring for a family member with HIV/AIDS (Buchan \& Calman). This is exemplified by a research study conducted in Kenya in 2003-2004 by the East Central and Southern Africa (ECSA) Health Community and Support for Analysis and Research in Africa-Academy of Educational Development (SARA-AED). The researchers found an average absenteeism rate of $15 \%$ in health workers due to time needed to care for a family members illness, illness of the health care worker themselves, or to attend a funeral (Munjanja et al., 2005). The HIV/AIDs pandemic has increased the workload on existing staff, potentially resulting in decreased morale and increased fatigue and burnout (Chen \& Evans, 2004). Caring for HIV/AIDs patients also requires an increased skill level of nurses and other health care workers (Chen \& Evans). The lack of personal protective equipment is considered to be a contributing factor for nurses developing HIV/AIDs (Chen \& Evans). The death rates of health workers in Malawi have increased five to six-fold in recent years, with $43 \%$ of the loss attributed to death of nurses. In South Africa, an estimated $14 \%$ of professional health workers are HIV-positive (Ogilvie et al., 2007). 
The internal and international migration issue has had a severe impact on the nursing workforce in sub-Saharan Africa (Ogilvie et al., 2007). Internal migration can be seen as nurses moving from rural areas to urban areas, the public sector to the private sector, and working in a nursing position to a non-nursing position (Ogilvie et al.). There are many contributing factors that 'push' nurses from their country of origin and 'pull' them to work in more developed countries. International migration is seen as nurses move from their country of origin, where they have obtained education and nursing skills, to a more developed country to continue to work as a nurse. Patterns of the migration of nurses have been identified by Ogilvie et al. Nurses were identified as moving from Malawi to Botswana or Swaziland; from Botswana or Swaziland to South Africa; from South Africa to the United Kingdom, the United States, Australia and Canada; from Ghana to the United Kingdom and to a lesser extent to the United States, Canada, and Australia. International migration can have devastating effects on the less developed and poorer countries, leaving more nursing vacancies unfilled, placing a larger workload on the existing nursing workforce, and draining important and limited healthcare resources; including education and training of nurses (Buchman \& Calman, 2004; Chen \& Evans, 2004). The international migration of nurses can also be viewed as a human rights issue (Ogilvie et al., 2007). Olgivie et al. listed several 'competing rights' for health professionals: the right to health of the populations in the origin and destination countries; the right to leave their country of origin to seek an improved quality of life; the right to work and find just and favorable work conditions; the right to a sustainable 
standard of living, right to education; and the right to be treated equally and without discrimination.

Push factors such as low wages, poor working conditions, decreased job satisfaction, limited opportunity for career advancement or advanced education all contribute to pushing nurses out of their home country (Ogilvie et al., 2007). In Ghana, two push factors for nurses were doctors not respecting nurses and not being able to utilize specialized nursing knowledge in their work place setting (Dovlo, 2006). The presence of war and political unrest can lead to destabilization of governments, which can cause a breakdown in human resources and social support of health care systems (Chen \& Evans, 2004). War and political unrest can also contribute to the cycle of poverty and inequality. An unstable political environment, fear of violence, and punishment of intellectuals have also been identified as push factors (Ogilvie et al., 2007).

The 'pull' factors that motivate nurses to participate in internal or international migration include: higher salaries; better working environment that may include a higher nursing staff ratio, increased access to medication and supplies for patient care; opportunities for in-service training; and additional education, and career advancement (Ogilvie et al.). Professional recognition of the role of nurses and support for nurses participating in leadership to help shape and implement policies directing health care is another 'pull' factor for internal and international migration of nurses (Roberts, 2008). Nurses have the opportunity to impact health within the health care system and beyond. This is because they can intervene at many different levels and in different arenas, including policy formation, research, health information, community care, partnering 
with civil society, and participating in the public sector such as ministries of health, education, and family and youth (Roberts). The motivation for migration of health professionals, including nurses, often comes from seeking education for themselves and their children and from seeking security and safety for their families. The opportunity to obtain work experience and live and work in a safe environment is just as important as salary (Roberts). The recruitment of nurses by higher income countries has increased and nurses fluent in English, such as nurses from Malawi, Zimbabwe, South Africa, and Ghana are in high demand (Ogilvie et al., 2007).

The WHO (2004) identified a strong correlation between the number of health care workers (physicians, midwives and nurses) per 1,000 population of people and coverage levels for immunization and births attended by skilled health professionals. This correlation is based on evidence available from the study of human resources for health. Considering this evidence, the WHO recommended a minimum of 2.5 physicians, nurses and midwives per 1,000 population (Lane, Antunes \& Kingma, 2009). Speybroeck, Kinfu, Dal Poz, and Evans (2006) identified a threshold of 2.5-2.28 health care workers (physicians, nurses and midwives) per 1,000 population. This health care worker density is associated with $80 \%$ coverage of deliveries with skilled birth attendants. Speybroeck et al. (2006), through statistical analysis, found improved health outcomes in countries with a higher density of health workers.

Nurses and midwives are estimated to be $71 \%$ of the world wide health care workforce (Lane et al., 2009). The WHO recommended 2.5 health workers per 1,000 population overall. More specifically, the WHO recommended that the number of nurses 
needed is 1.71 per 1,000 population, and stated that a critical deficit exists when staffing levels for health workers are below these recommended levels (Lane et al.). The nursing shortage is most acutely felt in low-income countries (LIC) where the numbers of skilled health professionals are critically low and the infrastructure for health care and medical supply levels are woefully inadequate (Olgilvie et al., 2007). In South Africa, between the years $2000-2003$, the number of nurses working decreased by $12 \%$ and 32,000 nursing vacancies existed. In Malawi in 2003, only $28 \%$ of vacant nursing positions were filled. Ghana's Ministry of Health reported similar increasing vacancy rates, and from 1998-2003, the Ministry of Health reported the nurse vacancy rates of 26-57\% (Olgilvie et al., 2007).

Looking ahead to the year 2015 and evaluating the estimated population growth and the number of nurses needed to care for this increased population, 31 sub-Saharan African LIC are identified as having a critical deficit of health service providers (Lane et al., 2009). In 2005, the 31 LIC's, four lower-middle income countries (LMIC), and one upper-middle income country in the sub-Saharan African region had an estimated number 540,000 nurses and midwives, with an estimated deficit of 598,000. A listing of LIC, LMIC and UMIC can be seen in Table 4. By the year 2015, the estimated size of the deficit of nurses and midwives in these critical deficit sub-Saharan African countries will reach 881,000 (Lane et al.). 
Table 4

Thirty-six sub-Saharan African Countries Classified by Income Level (Lane et al., 2009)

\begin{tabular}{|c|c|c|}
\hline No. & Income Level & Country name \\
\hline 1 & Low & Benin \\
\hline 2 & & Burkina Faso \\
\hline 3 & & Burundi \\
\hline 4 & & Central African Republic \\
\hline 5 & & Chad \\
\hline 6 & & Comoros \\
\hline 7 & & Cote d'Ivoire \\
\hline 8 & & Democratic Republic of the Congo \\
\hline 9 & & Eritrea \\
\hline 10 & & Ethiopia \\
\hline 11 & & Gambia \\
\hline 12 & & Ghana \\
\hline 13 & & Guinea \\
\hline 14 & & Guinea-Bissau \\
\hline 15 & & Kenya \\
\hline 16 & & Liberia \\
\hline 17 & & Madagascar \\
\hline 18 & & Malawi \\
\hline 19 & & Mali \\
\hline 20 & & Mauritania \\
\hline 21 & & Mozambique \\
\hline 22 & & Niger \\
\hline 23 & & Nigeria \\
\hline 24 & & Rwanda \\
\hline 25 & & Senegal \\
\hline 26 & & Sierra Leone \\
\hline 27 & & Togo \\
\hline 28 & & Uganda \\
\hline 29 & & United Republic of Tanzania \\
\hline 30 & & Zambia \\
\hline 31 & & Zimbabwe \\
\hline 1 & Lower middle & Angola \\
\hline 2 & & Cameroon \\
\hline 3 & & Congo \\
\hline 4 & & Lesotho \\
\hline 1 & Upper middle & Equatorial Guinea \\
\hline
\end{tabular}


When evaluating the nursing shortage, it is important to discuss the terms need, supply, and demand as they apply to the nursing shortage. As defined by Lane et al. (2009): the need for nursing staff identifies the "actual minimum number of workers estimated to be required to ensure quality of service as well as health outcomes"; the demand for nursing staff is "the number of positions that can be financially supported and that are open to health workers"; and the supply is "the actual available number of nurses to fill free positions" (p. 8). Many sub-Saharan African countries cannot hire new nursing graduates or experienced, qualified nurses into their health system due to lack of available finances (Lane et al.). Recently, in Kenya, half of the nursing positions remained vacant and one third of the nurses qualified to work were unemployed (Lane et al.). The health system in Zambia cannot provide jobs for the graduating nursing students and the number of nurses who work outside the country is higher than the number of graduating nursing students (Lane et al.). The Zambian General Nursing Council reported in 2003-2004 that they reviewed and processed 1,222 applications from nurses and midwives to work outside of the country, and 994 nursing students graduated from nursing schools in Zambia during those same years (Lane et al.). The United Republic of Tanzania reported to the International Council of Nurses that some of the nurses in this country are working for free to gain knowledge and skills to maintain their competencies so they may be considered for a future paid position (Lane et al.). 


\section{Health Reform and Restructuring}

Health sector reform and organizational restructuring refers to changing the overall health care system of a country to provide better efficiency, access to health care, and improved outcomes (Buchman \& Calman, 2004). While reorganization of a health care system is taking place in a country, or during a period of change and restructuring, it is critical to engage nurses in the process, planning, implementation, and evaluation of the change and restructuring. Reform efforts cannot disregard the coping strategies used by nurses and other health care workers such as taking an additional job in the private sector or a non-nursing position (Buchan \& Calman). Health reform that is sustainable and has a positive impact on health indicators is achieved through policy analysis and policy change that ensure the needed resources are available to support reform. 


\section{Policy Analysis}

The primary purpose of this paper is to analyze the nursing shortage in selected subSaharan African countries from a policy perspective using two frameworks, Fawcett and Russell (2005) and McLaughlin and McLaughlin (2008). The first framework, Fawcett and Russell's Conceptual Model of Nursing and Health Policy (2005), will be used to analyze the nursing shortage in sub-Saharan Africa from the perspective of nursing practice, access to nursing interventions, and social justice issues. The second framework is McLaughlin and McLaughlin's Policy Analysis Process (2008), which will be used to identify, analyze and make recommendations for health policy that provides a sustainable expansion of nursing capacity in sub-Saharan African countries.

\section{Policy Analysis Using Fawcett and Russell's Framework}

Fawcett and Russell (2001) developed the framework The Conceptual Model for Nursing and Health Policy to develop knowledge of health policy within the nursing profession. Fawcett and Russell (2005) later revised this framework in The Conceptual Model for Nursing and Health Policy Revisited. The revised framework consists of four levels of nursing and health policy focus outcomes. The four levels are interacting and increase in scope with each level.

The levels evaluate: how effective nursing practice processes are on individual, family, group, and community health outcomes (Level 1); the efficiency of the nursing practice delivery systems (Level 2); specific health care delivery systems and their effectiveness and efficiency in specified geopolitical communities (Level 3); and how equal the access is to effective and efficient nursing practice and nursing practice delivery 
systems in the global community (Level 4). Health care services are evaluated from a social justice perspective (Fawcett \& Russell). The framework can be applied to the nursing shortage in sub-Saharan African countries using these four interacting levels of analysis. Next, each level will be analyzed and discussed.

In level 1 , the effectiveness of nursing practice on health outcomes for communities is evaluated. In this level, the framework can be applied to three of the Millennium Development Goals (MDGs) developed by the United Nations: MDG 4, 5 and 6. These goals include reducing by two-thirds the under-five mortality rate, decreasing by three quarters the maternal mortality ratio, and halting and beginning to reverse the spread of HIV/AIDS and other diseases by 2015, respectively (Global Health Workforce Alliance [GHWA], 2008; United Nations, 2009) To achieve MDG 4 (reducing by two-thirds the under-five mortality rate), it will be crucial to increase the number of health workers, including nurses and midwives, and to maximize the use of the health care workers already in place (GHWA). A positive correlation has been found between the number of health workers available to work and care for a population and improved health outcomes. The number of health care workers is important when evaluating changes in rates for maternal mortality, infant mortality and under-five mortality and immunizations in different countries (GHWA). It is essential to have trained health workers such as midwives, nurses, or doctors to assist and support the prenatal, intranatal and postpartum stages in order to decrease maternal and newborn morbidity and mortality (Dreesch et al., 2005). 
Level 2 examines the effectiveness and efficiency of health care delivery subsystems, including health care delivered by nurses and other health care professionals, on health outcomes (Fawcett \& Russell, 2005). In Malawi, where the nursing/midwifery personnel are 6 per 10,000, the maternal mortality ratio per 100,000 live births is 1,100 and the infant mortality rate per 1,000 live births is 76 (WHO, 2008). In South Africa, where the nursing/midwifery personnel rate is almost seven times Malawi's rate at 41 per 10,000, maternal mortality and infant mortality rates are significantly better. Maternal mortality rates per 100,000 are 400 , and the infant mortality rate per 1,000 live births is 56 (WHO, 2008). The health indicator and the rates of personnel can be seen in Table 2. When the density of health workers (the number of doctors, nurses and midwives per 1,000 population) increases, the maternal, infant, and under-five mortality decreases, and the greatest area of impact is maternal mortality (Chen \& Evans, 2004). Statistical analysis reveals that with a $10 \%$ increase in health workers, there is a $5 \%$ decline in maternal mortality and a two percent decline with infant and under-five mortality (Chen \& Evans).

Level 3 examines the social requirements for the equity of access to effective nursing practice processes and nursing practice delivery systems that are efficient. It also examines the equality of the distribution of the costs and burdens for health care delivery (Russell \& Fawcett, 2005). In Malawi, a country with one of the highest shortages of nurses, working conditions are difficult and hospitals do not have enough resources to accommodate patients. Many have complicated conditions such as pneumonia or tuberculosis, which is often related to HIV/AIDs. According to the Chief Nursing Officer 
at Kamuzu Central Hospital, one of the largest state referral hospitals in Malawi, the nursing shortage is critical (WHO African Regional Report, 2006). She stated that in a hospital ward with 70-80 patients, 10-12 nurses were needed on each ward, but the hospital had only 5 nurses for each ward. In March 2005, the hospital needed 532 nurses to be fully staffed, but had only 188 nurses to staff the hospital (WHO African Regional Health Report, 2006). The director of the hospital, Dr. Damson Kathyola, noted that the nursing shortage at his hospital is, "a crisis, which if not reversed, could lead to the collapse of the entire health delivery system in Malawi" (WHO African Regional Health Report, 2006, p. 118).

In developing countries, the most underserved areas are most often the rural areas. Job and career opportunities are more plentiful in urban areas. In South Africa, in rural areas, the average ratio of nurses is approximately 15 nurses per 10,000 population compared to urban areas with rates of approximately 55 per 10,000 population. The average ratio in South Africa for nurses is approximately 32 per 10,000 population (Buchman \& Calman, 2004).

Level 4 of the framework examines the quality, cost, and access to health care in the context of justice: how health policies allocate health care services (Russell \& Fawcett, 2005). Throughout the history of nursing, nurse leaders, such as Florence Nightingale, Lillian Wald, Lavinia Dock, and Margaret Sanger included social justice in their nursing practice when they pursued political activity and public health interventions that would improve the health of populations (Tyler-Viola et al., 2009). Nurses are the largest group of health professionals who provide health care in multiple settings such as cities, 
villages, critical care units, clinics, care of the elderly, nursing education, and advanced practice. In order to have nurses address social responsibility and justice issues now and in the future, it is important to establish a global nursing agenda for nursing education and to incorporate social justice into nursing education, nursing leadership and professional practice (Tyler-Viola, et al., 2009).

The Global Health Workforce Alliance (GHWA) of the WHO was created to develop solutions to address the lack of health care workers, including nurses. They developed the following five strategies to address these needs:

1. Mobilize direct financial support for health training institutions;

2. Develop training partnerships between resource-rich and resource-limited countries;

3. Nurture a new generation of academic leaders with experts in the clinical, public health, and other sciences, from around the world;

4. Develop innovative approaches to teaching in resource limited settings with state of the art teaching materials and continuing education through information and communication technology; and

5. Assistance with the creation of planning teams to address health workforce shortages (Tyler-Viola, et al., 2009, p.115-116).

The cost of providing health care and how much a country is able or willing to spend on health care has a direct impact on the success of addressing the health care needs, meeting the MDGs, and looking at the long term economic success of the country (WHO \& GHWA, 2008). The cycle of poverty includes a high birth rate, poor health, and low 
economic growth. To break this cycle and to provide an opportunity for good health for the general population, a country's leaders need to ensure adequate spending on health care. This includes providing effective health services, sustainable reproductive health policies, and access to nutrition to ensure economic growth and alleviate poverty (WHO \& GHWA).

The WHO Commission on Macroeconomics and Health (2001) calculated that universal health care services would cost $\$ 34$ per capita (US). This small cost is predicted to decrease child mortality by two-thirds, maternal mortality by three-quarters, and to significantly decrease communicable disease. Expenditure of $\$ 44$ per capita (US) would provide this universal access and include training of a sufficient number of health care workers to provide these services (WHO \& GHWA, 2008). To effectively reduce the nursing shortage and provide equal access to quality healthcare, governments, partners, and nurses need to work together to develop sustainable policies to train, mentor, and expand nursing practice that has solid financial support to bring these policies to fruition.

Next, the nursing shortage in sub-Saharan African countries will be analyzed according to McLaughlin and McLaughlin's Policy Analysis Process (2008).

\section{McLaughlin and McLaughlin Policy Analysis Framework}

The Policy Analysis Process framework of McLaughlin and Mc Laughlin (2008) uses six stages to analyze health policy. Stage 1 identifies the problem, that is, how the nursing shortage is defined in the sub-Saharan African countries. Stage 2 analyzes the nursing shortage in sub-Saharan Africa compared to other countries around the world. Stage 3 examines the process: 'How are the sub-Saharan African countries managing the nursing 
shortage?' Stage 4 uses qualitative analysis to examine how the nursing shortage is impacting the quality, equity, and distribution of health care and how these affect health indicators. Stage 5 evaluates current policy, solutions, and feasibility of solutions that are sustainable to increase nursing capacity. Stage 6 provides recommendations and discussion of what can be done to assist sub-Saharan African countries to scale up nursing capacity. The nursing shortage in sub-Saharan Africa will be briefly reviewed using McLaughlin and McLaughlin's framework.

Stage 1 defines the problem of the nursing shortage in sub-Saharan Africa. Nurses and midwives are estimated to be $71 \%$ of the world wide health care work force (Lane et al, 2009). The WHO recommended 2.5 health workers per 1,000 population overall. More specifically, the WHO recommended that the number of nurses needed is 1.71 per 1,000 population, and stated that a critical deficit exists when staffing levels for health workers are below these recommended levels (Lane et al, 2009). The nursing shortage is most acutely felt in low-income countries (LIC) where the numbers of skilled health professionals are critically low and the infrastructure for health care and medical supply levels are woefully inadequate (Ogilvie et al., 2007). In South Africa, between the years 2000-2003, the number of nurses working decreased by $12 \%$, and 32,000 nursing vacancies existed. In Malawi in 2003, only $28 \%$ of vacant nursing positions were filled. Ghana's Ministry of Health reported similar increasing vacancy rates, and from 19982003, the Ministry of Health reported nurse vacancy rates of 26-57\% (Ogilvie, et al).

In Stage 2, it is important to analyze how the nursing shortage in sub-Saharan Africa compares to other countries. In Asia, which has 50\% of the world's population and $30 \%$ 
of the doctors, nurses and midwives, the shortage of nurses and other health care workers is not as severe. Europe and North America combined have 20\% of the world's population, $50 \%$ of the doctors, and $60 \%$ of the nurses. The average nurse to population density in sub-Saharan Africa is 1 per 1000 population, compared to the average nurse to population density in Europe and North America, which is 10 per 1000 population. In dramatic contrast, Finland has a nurse and midwife density of 22 per 1000 population, while Uganda's nurse and midwife density is 0.09 per 1000 population. Many countries in sub-Saharan Africa have the same or fewer health workers today compared to 30 or 40 years ago (Chen \& Evans, 2004). Table 5 illustrates the nurse availability in selected sub-Saharan African countries compared to recipient countries. Ironically and compounding the problem, the sub-Saharan countries with low number of nurses are seeing their nurses migrate to countries with a much higher number of nurses (Dovlo, 2005). 
Table 5

Nurse Availability Data in Selected sub-Saharan African Countries (WHO, 2006)

\begin{tabular}{lrclc} 
Country & Stock & $\begin{array}{c}\text { Stock per 1,000 } \\
\text { Population }\end{array}$ & \multicolumn{2}{c}{$\begin{array}{c}\text { Compare Stock per 1,000 pop. in } \\
\text { some recipient countries }\end{array}$} \\
\hline Botswana & 4,753 & 2.65 & United States & 9.37 \\
Burkina Faso & 5,518 & 0.14 & United Kingdom & 12.12 \\
Cameroon & 26,042 & 1.60 & Ireland & 15.2 \\
Central Africa & 1,188 & 0.30 & Canada & 9.95 \\
Republic & & & Australia & 9.71 \\
Ghana & 19,707 & 0.92 & New Zealand & 8.16 \\
Kenya & 37,113 & 1.14 & France & 7.24 \\
Madagascar & 5,661 & 0.32 & Portugal & 4.36 \\
Malawi & 7,264 & 0.59 & & \\
Mauritius & 4,550 & 3.69 & & \\
Nigeria & 210,306 & $1.70(2003)$ & & \\
Senegal & 3,287 & 0.32 & & \\
Seychelles & 634 & 7.93 & & \\
South Africa & 184,459 & 4.08 & & \\
Tanzania & 13,292 & 0.37 & & \\
Uganda & 16,221 & 0.61 & & \\
Zambia & 19,014 & 1.74 & & \\
Zimbabwe & 9,357 & 0.72 & & \\
& & & & \\
\end{tabular}

Stage 3 of the McLaughlin and McLaughlin framework assesses how the sub-Saharan African countries are managing the nursing shortage. When evaluating the nursing shortage in a respective country, policy makers need to consider availability of financial resources, the ability of the job market to employ health workers, and the capacity to design effective strategies for management and retention of health workers. Policy makers in many sub-Saharan African countries have developed national human resources for health plans (GHWA \& WHO, 2008). This plan includes short-term and long-term goals that reflect the health needs of the population and decrease the burden of disease. In 
addition, the plan needs to be creative, to introduce new roles, technologies, and practices, and to decrease attrition and migration. The plan also needs to include these health needs when planning education and training of nurses and other health workers (GHWA \& WHO). Reaching the Millennium Development Goals (MDG) has motivated many countries to develop and put into place an 'essential health package.' This essential health package puts the focus on the major burden of disease in the country, areas of greatest need, and 'appropriately trained' health workers. As defined by the MDG, 'appropriately trained' has three definitions. First, the country's health needs are incorporated into the education and training programs. Second, the skill mix and competencies of health care workers have the greatest impact on health outcomes. Third is the goal of having a more equitable distribution of health workers in geographical areas, especially poor and rural areas (GHWA \& WHO). For example, in Malawi, a short-term goal is to maximize existing training capacity and recruit overseas staff, retired staff, and those who left the health care positions. A long-term goal is the education and training of 11 priority cadres, using tutor-incentive programs as an incentive for nurses and other health workers to take positions. In Kenya, e-learning programs, which are computer-based training, take place in hospitals, nursing colleges, health centers, and on the job mentoring to upgrade enrolled nurses to registered nurses (GHWA \& WHO, 2008).

Stage 4 of the McLaughlin and McLaughlin framework analyzes how the nursing shortage impacts the quality, equity, and distribution of health care. Three examples of nurses making a positive impact on health and health care outcomes can be seen in South 
Africa, Lesotho, and Rwanda. Nurse initiated anti-retroviral therapy (ART) has been implemented on a small scale with great success, improving the quality, equity and distribution of health care significantly. In the first example, the city of Luisikisiki, South Africa, is one of the poorest, most densely populated rural areas in South Africa with 150,000 inhabitants. In this city, there is one hospital and 12 clinics, five physicians per 100,000 population, and an extremely high HIV prevalence, with $31 \%$ of the women seen at the antenatal care clinics being HIV positive (Bedelu, Ford, Hilderbrand, \&Reuter, 2007). Medicins Sans Frontieres implemented a nurse-initiated ART program from 2004-2006 in which nurses managed non-complex cases in the clinics. The complex cases were referred to the hospital where specialist physicians provided treatment. The outcomes were impressive: after 12 months, only $2 \%$ were lost to follow-up for the clinics, while $19 \%$ were lost to follow-up in the hospitals. This was attributed to proximity, decreasing barriers, and to the variables of community engagement and contacts with adherence counselors. To allow hospitals to effectively deliver complex care, $81 \%$ of HIV/AIDS cases were managed by the clinics (Bedelu, et al.).

Lesotho is a small, landlocked, independent country, located in the mountains in the southeastern area of South Africa, with an estimated population of 2,130,819 in 2009 (CIA, 2009). The country of Lesotho has been devastated by HIV/AIDS, having the third highest HIV prevalence globally, with 270,000 people living with AIDS (Cohen, Lynch, Bygrave, \& Eggers et al., 2009). In addition, Lesotho has the fourth highest TB incidence globally: $90 \%$ of TB patients are HIV positive, and life expectancy is just 36 years (Cohen et al.). 
AIDS accounts for $56 \%$ of the deaths under 5 years of age. Poverty affects approximately $84 \%$ of the population, with 1.8 million inhabitants living below the poverty line (Cohen et al.). The healthcare workforce infrastructure is significantly below the recommended WHO levels, with 5 physicians and 62 nurses per 100,000 population compared to South Africa with 74 doctors and 393 nurses per 100,000 population (Cohen et al.).

The Medicins Sans Frontieres Initiative, 2006-2009, in the Scott catchment area of Lesotho provided intensive ART training, clinical mentorship, and support by one physician per each district. Lay counselors were trained for HIV/TB counseling in their role as support staff; 14 rural health centers were staffed by nurses only. In Lesotho, several positive outcomes were achieved, including: $80 \%$ of patients on ART were initiated at the clinic level; at the clinics there was an $89 \%$ retention rate at 12 months, $80 \%$ at 24 months versus $79 \%$ and $75 \%$ in sub-Saharan Africa; $80 \%$ of the patients were still in treatment at 12 months and $76.5 \%$ at 24 months; $89.4 \%$ of children were still in care at 12 months and $85.5 \%$ of children at 24 months (Cohen et al.). Indicative of patients seeking treatment earlier, the population participating in the initiative had a lower rate of presenting with extremely low CD4 count (less than 50), from 22\% in 2006 to $11.9 \%$ in 2008 (Cohen, et al.)

Rwanda is a sub-Saharan African nation with 9 million inhabitants, $80-90 \%$ of whom live in rural populations. Although the government prohibits nurse-initiated ART, they allowed Family Health International to develop a task-shifting model to assess nurseinitiated ART (Shumusho et al., 2009). Intensive training of nurses by physicians was 
conducted. Nurses performed assessments, ordered and interpreted labs, prescribed ART to non-complex cases, and referred children and complex cases to physicians. Under this model, physicians provided support as needed and provided weekly supervision. The primary care centers were chosen for this project. Again, outcomes were positive for nurse-initiated ART. Nurses successfully identified eligibility for ART, with 622 patients correctly determined ineligible (Shumbusho et al.). Of the 451 who were eligible, $96 \%$ began ART, as compared to $80 \%$ at the other facilities. Retention rates were better in these pilot primary health care centers compared to the other facilities, with $92 \%$ continuing ART at 12 months and $91 \%$ at 24 months compared to $80 \%$ at the other facilities. The fact that the most complex cases were sent to the other facilities confounds the outcomes for this comparison, but it is clear that the outcomes for nurse-initiated therapy are not significantly worse than those managed by physicians. If the number of nurses were increased, the health indicators would be positively impacted and continue to improve.

Stage 5 explores current policies, solutions, and the feasibility of these solutions that are sustainable to increase nursing capacity. Judith Oulton (2006) identified five areas for policy intervention to address the global nursing shortage. These five areas can also be applied to the nursing shortage in sub-Saharan Africa. The five areas for policy intervention are: 1) macroeconomics and health sector funding policies; 2) workforce policy and planning, including regulation; 3) positive practice environments and organizational performance; 4) retention and recruitment which also addresses in-country inadequate distribution and out-migration; and 5) nursing leadership. 
Macroeconomics and health sector funding focuses on several core areas. Infrastructure that support nursing and patient care, such as electricity, sanitation, and water for baths needs to be provided. Donor financing for salaried positions in health care systems and training facilities will help to resolve safety issues with patients and staff and recruitment and retention of nurses (Oulton, 2006). When health policy makers allocate funding, health care needs should be a required area for funding. It is critical for nurses to have an understanding of the relationship between macroeconomics and health. Nurses as a professional group should build strong relationships with many different stakeholders such as the World Bank. The strengthening of nursing organizations will also help to address contributing factors to the nursing shortage and advance the nursing profession (Oulton).

Workforce policy, planning, and regulation call for broad and increased nursing involvement. Nurses should be involved in workforce planning and best practice guidelines. It is critical to increase the number of nurses and to redistribute the workforce in urban and rural areas. In South Africa, $81 \%$ of nurses work in cities where only $54 \%$ of the population lives (Oulton, 2006). To help meet the nursing shortage in sub-Saharan Africa, new roles for nurses, such as advanced practice roles, should be created and expanded to help meet the health care needs. When health care policy makers in governments make decisions about funding health care, it is crucial for nurses to be at the policy table to help shape policy making for health care spending. Sustainable solutions to bridge nursing education and service need to be developed. Nurses must join together to address important health policy and health care issues (Oulton). 
Positive practice environments help to create an improved working environment for nurses. One area of immediate need in the practice environment is the workload of the nurse. One nurse in South Africa reported that in the hospital where she worked, there was one nurse for 18 beds. In the outpatient department, 14-15 nurses were assigned to 500 outpatients (Yumkella, 2006). In Australia, when patient ratios were mandated in legislation, nurses began to return to work on their own (Oulton, 2006). Implementing supportive policies for nurses such as flexible staffing, family friendly policies, and increased autonomy will help to lower nursing vacancy and turnover rates (Oulton). Other solutions to help to contribute to a positive working environment are addressing and improving occupational health and safety standards, encouraging good working relationships between health care teams, building stronger management, and expanding the nurse's role to delegate and supervise (Oulton).

Retention and recruitment involves many areas and requires targeted incentives that are equally distributed. In South Africa, nurses were given half of the percentage increase than doctors to work in rural areas (Oulton, 2006). Controlling 'in' migration, 'out' migration, and encouraging 'returning' migration as well as fighting for ethical nurse recruitment, both in country and outside of the country, will improve retention of nurses. Other policies to increase retention and recruitment of nurses are to offer increased salaries and benefits and provide student grants to draw new nursing students and retain current students (Oulton). Offering local incentives including free HIV/AIDS and chronic care to nurses and their families, an incentive which will provide for a healthier population, retain nurses in the workforce, and give nurses motivation to stay 
employed in their country of origin could have a significant impact for retention and recruitment of nurses (Oulton).

Nursing leadership is a critical area of policy to address in terms of the nursing shortage in sub-Saharan Africa. Nurses continue to stress the importance of training and education to promote strong leadership skills for nursing leaders. Solutions that can be offered to strengthen nursing leadership include: continuing education to develop nurse executives who have strong leadership skills; offering and encouraging participation in ICN Leadership programs; developing skills to initiate policy and effective lobbying; and creating and supporting national, regional and international leadership networks (Oulton).

In Stage 6 of the McLaughlin and McLaughlin framework, recommendations related to how to address the nursing shortage in sub-Saharan Africa are made and current interventions to expand education and increase retention from selected countries are evaluated. In Kenya, there are an estimated 20,000 nurses. Of these, $85 \%$ have training at the certificate level (enrolled nurses). This means they do not have a registered nurses' diploma and are not fully qualified to manage the major diseases facing the sub-Saharan region, including HIV, tuberculosis, and malaria (African Medical and Research Foundation (AMREF), 2010). Enrolled nurses make up 70\% of the nursing workforce and $45 \%$ of the overall health workforce in Kenya (AMREF). Enrolled nurses are usually the first contact with the health care system for communities. Educational training for the registered nurses' diploma is classroom based, and only 100 nurses each year qualify for this program. To address this issue, AMREF and the Nursing Council of Kenya (NCK) 
are shifting education from classroom teaching to paper-based distance learning and eLearning (AMREF).

The goals of the eLearning Project are to register almost 20,000 nurses by the year 2011 and to be an example for replication of this program in other African countries. The eLearning Program is comprised of 32 medical training colleges and nursing schools as well as AMREF's Virtual Nursing School. The program has 105 computer equipped training centers in eight provinces that include: rural, remote and marginalized districts; over 5,400 nurses enrolled on both the eLearning and print-based learning modules; 494 computers in the training centers; over 200 implementers of the program are trained in IT skills. Three benefits of this eLearning program are flexibility, interactivity and accessibility. The flexibility of this program allows students to learn anytime, anywhere, and while they work. The interactivity of the program develops nurses' IT skills. The accessibility of the program is extremely high with access to courses through learning centers open 24 hours, seven days a week. This eLearning program improves health care through a new electronic infrastructure that is accelerating nursing education (AMREF, 2010).

Strategies for expanding the capacity for educating nurses have been explored by countries in sub-Saharan Africa. For example, Botswana has increased enrollment in schools of health science. In Lesotho, new faculty for health science were hired and a bilateral agreement with the free state university to address training and retention was made. In Malawi, there has been an attempt to increase the training and production of nurse midwives and enrolled nurses. Mozambique created two higher institutes for Health 
Staff training in Beira and Maputo. Zambia reviewed the curriculum and implemented short courses to update skills of current nurses. Nursing schools are awarding diplomas instead of certificates for registered nurses and a new nursing masters program has been proposed (Dovlo, 2007). In South Africa, a master nursing degree is available to help increase the number of advanced practice nurses in this country. (University of Witwatersrand, 2010).

Several retention strategies to address the nursing shortage have been implemented in many sub-Saharan African countries. Increasing and supplementing salaries is one important area to address when trying to retain and increase nursing capacity. For example, in Botswana, a 30\% overtime allowance has been given to nurses. Hardship and rural allowances, to increase the number of nurses in rural areas, have also been distributed in Namibia, Zambia, and South Africa (Family Health International, 2008).

Non-monetary strategies have also been offered to retain and attract nurses and health care workers. In Swaziland, institutional housing was offered to health professionals. Zambia piloted a car loan system for health workers and developed an action plan for housing loans (Dovlo, 2007). Recruitment of nurses from their country of origin has contributed significantly to and exacerbated nursing shortages in many sub-Saharan countries. International and inter-country agreements between recipient countries and developing countries are needed to effectively manage and decrease the impact of nursing shortages in developing countries (Dovlo). These agreements also present a solution to manage the rights of health workers and at the same time allow developing countries to provide an adequate number of nurses to care for their own populations (Dovlo). 


\section{Summary}

The primary purpose of this paper was to analyze the nursing shortage in selected subSaharan African countries from a policy perspective using two frameworks, Fawcett and Russell (2005) and McLaughlin and McLaughlin (2008). Policy advocacy is a critical nursing role that has deep roots in the history of nursing. Specifically, health policy, including health services, health care personnel, and health care expenditures, impacts the nursing shortage and health outcomes in sub-Saharan Africa. The sub-Saharan African nations face many health challenges including communicable and non-communicable diseases. The pandemic of HIV/AIDs has had profound effects on sub-Saharan African societies. The co-morbidities of malaria and tuberculosis have compounded this problem and contributed significantly to morbidity and mortality. Diabetes, cardiovascular disease, and cancer are undertreated due to lack of resources, including access to nursing care, resulting in higher morbidity and mortality. Sub-Saharan Africa faces a nursing shortage presenting complex problems with far reaching consequences affecting millions of people in the sub-Saharan region. Four of the MDGs are directly influenced by nursing interventions: reducing infant and under-five mortality by two-thirds; reducing maternal mortality by three-fourths; halting and reversing HIV/AIDs, tuberculosis, and malaria epidemics; and reducing by half the people experiencing hunger (Buchan \& Calman, 2004). The WHO calls for $140 \%$ increase in health care workers to overcome the shortage in sub-Saharan Africa (WHO, 2006). Barriers to reaching this goal include inefficient nursing education infrastructure, increased nursing workforce demands related 
to the impact of HIV/AIDs, the internal and international migration of nurses, achieving health sector reform and reorganization.

\section{Conclusions}

The nursing shortage is managed by the health policies established in each country. Policy analysis is required to develop health care and practice policies that are effective, efficient, and equitable to provide sustainable solutions to increase nursing capacity and ensure positive health outcomes for the population in the sub-Saharan African countries. Fawcett and Russell's Framework (2005) provides guidance in analyzing the nursing shortage in sub-Saharan Africa from the perspective of nursing practice, access to nursing practice, and social justice issues. Fawcett and Russell use four interacting levels of analysis including:

1. The effectiveness of nursing practice processes on individual, family, group, and community health outcomes;

2. The efficiency of the nursing practice delivery systems;

3. The effectiveness and efficiency of specific health care delivery systems in specified geopolitical communities;

4. The equality of access to effective and efficient nursing practice and nursing practice delivery systems in the global community.

The policy analysis framework of McLaughlin and McLaughlin (2008) facilitates examination of the procedure of health policy analysis. This process is evaluated using the six stages of analysis proposed by McLaughlin and McLaughlin: 
1. Identification of the problem, that is, how the nursing shortage is defined in sub-Saharan African countries;

2. Analysis of the nursing shortage in sub-Saharan Africa compared to other countries around the world;

3. Examination of the process: how are the sub-Saharan African countries managing the nursing shortage;

4. Use of qualitative analysis to examine how the nursing shortage is impacting the quality, equity, and distribution of health care and how these affect health indicators;

5. Evaluation of current policy, solutions, and feasibility of solutions that are sustainable to increase nursing capacity;

6. Provision of recommendations and discussion of measures to be taken to assist sub-Saharan African countries to scale up nursing capacity.

Nurses, as the largest professional group within the health professions and usually the first contact with the public for health care, have a powerful role in health care advocacy. Nurses and midwives are estimated to comprise $71 \%$ of the global health care workforce. It is critical for nurses to unite and have a seat at the table with governments and donor organizations. Nurses need to take part in developing and implementing health care policy that supports increases in nursing capacity, expands the role of nurses, and ensures positive health care outcomes for the populations they serve. 
The advanced practice nurse plays a critical role in health policy, including education, practice, and research. To increase nursing capacity, nursing education should be expanded to support a sustainable scale up of the nursing workforce. Increasing efficiency of the nursing infrastructure, such as updating nursing curricula to focus on the health needs of the communities, increasing the number of nursing faculty, expanding the number of classrooms and nursing laboratory space, and offering more clinical opportunities are critically needed. The e-learning project in Kenya could be replicated in other countries with the expansion of internet access and use of computers, allowing more nurses to be trained. Nursing leaders could collaborate to form regional nursing educational centers, supported and accessed by neighboring countries. Offering expanded nursing curricula that focuses on the advanced practice roles of nurses and pooling resources to increase nursing capacity at the advanced practice level are other viable options.

Nursing practice can have a positive impact on health outcomes and indicators in subSaharan Africa with the scale up of nurses and midwives. This should be studied to identify the specific impact that nursing interventions have on the morbidity and mortality of the populations they serve. Data systems for nurses need to be generated in order to generate an accurate database and tracking system of all nursing personnel in each sub-Saharan African country (Riley et al., 2007). This is especially needed in the lower income countries. An up-to-date database would allow each country to plan effectively for expanding nursing services and to provide for the health care needs of their citizens. 
Nursing practice in sub-Saharan African countries can be enhanced by strengthening nursing organizations to guide practice and to give a voice to nurses. With a unified voice nurses can help shape health care policy at a local and national level, as well as reach out to partners and international organizations to obtain a long-term commitment to funding of nursing education and expanding infrastructure. Nursing leaders should develop resources to train nurses in human resource management, leadership skills, and mentoring new nurses. Current nursing roles can be expanded and new advanced practice nursing roles can be created to help meet the health needs of the population.

The nursing shortage in sub-Saharan Africa demonstrates a great need for health care in this region, but also presents a great opportunity for nurses to unite, expand their role in their practice to provide health care, and to participate in the development of health policy. Nurses can provide, through their practice and leadership, sustainable solutions to address the nursing shortage in sub-Saharan Africa, which will benefit the vast populations living in this region. 


\section{References}

African Health Monitor (2008, January-June). Fighting non-communicable diseases: africa's new silent killers. 8, 1-19. Retrieved March 1, 2010 from http://www.afro.who.int/en/media-centre/newsletters-bulletins/african-healthmonitor.html.

African Medical and Research Foundation (2010). Upgrading 20,000 nurses in kenya. Retrieved April 19, 2010 from source.

Bedelu, M., Ford, N., Hilderbrand, K. \& Reuter, H. (2007). Implementing antiretroviral therapy in rural communities: the lusikisiki model of decentralized hiv/aids care. The Journal of Infectious Diseases, 196, 464-468.

Bischoff, A., Ekoe,T., Perone, N., Slama, S., \& Loutan, L. (2009). Chronic disease management in sub-saharan Africa: whose business is it? International Journal of Environmental Research and Public Health,6, 2258-2270.

Bodenheimer, T., MacGregor, K., Stothart, N. (2005). Nurses as leaders in chronic care. British Journal of Medicine, 330, 612-613.

Buchan, J. \& Calman L. (2004). The global shortage of registered nurses: an overview of issues and actions. Retrieved from source March 11, 2009.

Chen, L. \& Evans, T. Joint Learning Initiative (2004). Human resources for health overcoming the crisis joint learning initiative. Retrieved from source March $20,2010$.

Cohen, R., Lynch, S., Bygrave, H., Eggers, E., Vlahakis, N., Hilderbrand, K., 
Knight, L., Pillay, P., Saranchuk, P., Goemaere, E., Makakole, L., \& Ford, N. (2009). Antiretroviral treatment outcomes from a nurse-driven, community supported HIV/AIDs treatment programme in rural lesotho: observational cohort assessment at two years. Journal of the International AIDS Society, $12: 23,1-8$.

Dovlo, D. (2007). Migration of nurses from sub-saharan africa: a review of issues and challenges. Health Research and Education Trust, 42, 1373-1388.

Dreesch, N., Dolea, C., Dal Poz, M.R., Goubarev, A., Adams, O., Aregawi, M., Bergstrom, K., Fogstad, H., Sheratt, D., Linkins, J., Scherpbier, R. \& Yousseff-Fox, M. (2005). An approach to estimating human resource requirements to achieve the millennium development goals. Retrieved March $20,2010$.

International Council of Nurses (2010). Delivering quality, serving communities: nurses leading chronic care. Retrieved from source May 22, 2010.

Lane, C., Antunes, F.A. \& Kingma, M. (2009). The nursing community, public finance policies: towards a better understanding. Retrieved March 11, 2009 from source.

Mathauer, I. Imhoff, I. (2006). Health worker motivation in africa: the role of non-financial incentives and human resource management tools. Human resources for Health, 4, 1-17.

McLaughlin C.P. \& McLaughlin, C.D. (2008). Chapter 1. Health Policy analysis an interdisciplinary approach (pp. 1-10). Boston: Jones and 
bartlett Publishers.

Munjana, O.K., Kibuk, S., Dovlo, D. (2005). Issue 7 the nursing workforce in sub-saharan africa. Retrieved from source February 21, 2009.

Naruse, K., Tashiro, J., Sakyo, Y., Ichikawa, W., \& Karani, A.K. (2008). stakeholders' perception of the desired master's program for kenya in community health nursing: areas of competency. Japan Journal of Nursing Science, 5, 61-67.

Ogilivie, L., Mill, J.E., Astle, B., Fanning, A., \& Opare, M. (2007). The exodus of professionals from sub-saharan Africa: balancing human rights and societal needs in the twenty-first century. Nursing Inquiry, 14, 114-124.

Oulton, J. (2006). The global nursing shortage: an overview of issues and actions. Policy, Poltics, \& Nursing Practice, 7, 34-39.

Riley, P.L., Vindigni, S.M., Arudo, J., Waudo, A.N., Kamenju, A., Ngoya, J., Oywer, E.O., Rakuom, C.P., Salmon, M.E., Kelley, M., Rogers, M., St. Louis, M. E. \& Marum, L.H. (2007). Developing a nursing database system in kenya. HSR: Health Services Research, 42, 1389-1405.

Roberts, J.H. (2008). The impact of global inequities on health professional migration. Policy, Politics and Nursing Practice, 9, 323-327.

Russell, G.E., \& Fawcett, J. (2005). The conceptual model for nursing and health policy revisited. Policy, Politics and Nursing Practice, 6, 319-326.

Shumbusho, F., van Griensven, J., Lowrance, D., Turtate, I., Weaver, M.A., Price, J., Binagwaho, A. (2009). Task shifting for scale-up of hiv care: evaluation of 
nurse-centered antiretroviral treatment at rural health centers in rwanda. PLoS Medicine, 6:10, 1-12.

Spreybroeck, N., Kinfu, Y., Dal Poz, M.R. \& Evans, D.B. (2006). Reassessing the relationship between human resources for health, intervention coverage and health outcomes. Background paper prepared for The world health report 2006 - working together for he alth (pp. 1-12). Geneva: World Health organization.

Tyeler-Viola, L., Nicholas, P.K., Corless, I.B., Barry, D.M., Hoyt, P., Fitzpatrick, J.J., \& Davis, S.M. (2009). Social responsibility of nursing: a global perspective. Policy, Politics, \& Nursing Practice, 10, 110-119.

University of the Witwatersrand, Johannesburg, SA (2010). Postgraduate programs, retrieved from source April 24, 2010.

World Bank (2009). Health indicators, retrieved April 3, 2010 from source.

World Health Organization (2006). National health systems - Africa's big public health challenge. African Regional Health Report (pp. 105-127). Geneva: The World Health Organization.

World Health Organization (2006). Fact sheet number 302, the global shortage of health workers and its impact. Retrieved February 15, 2009 from http://www.who.int/mediacentre/factsheets/fs302/en/print.html.

World Health Organization \& Global Health Workforce Alliance, (2008). Scaling up, saving lives task force for scaling up education and training for health workers. Retrieved June 13, 2009 from source. 
World Health Organization (2008). Health indicators. Retrieved from source March 13,2010.

Yumkella, F. (2006). Retention of health care workers in low-resource settings: challenges and responses. Retrieved April 17, 2010 from source. 